\title{
Resenha
}

\section{CASTELO, Carmen Velayos. Rachel Carson: la revolución entrañable. Salamanca: Ediciones Universidad de Salamanca, 2020. 123p.; ISBN: 978-84-1311-247-3}

\author{
ELISA TAVARES DUARTE
}

Universidad de Salamanca | Usal

Espera-se de um livro, primeiramente, que a sua leitura seja prazerosa. Ao tratar-se de uma obra fruto de um trabalho de pesquisa, soma-se a expectativa de reconhecer, entre as suas linhas, o rigor empregado em sua elaboração, desde as etapas iniciais da investigação científica até a redação final. Tudo isso encontrarão o leitor e a leitora na obra Rachel Carson: la revolución entrañable, de Carmen Velayos Castelo. A autora é professora de filosofia moral e política da Faculdade de Filosofia da Universidade de Salamanca (Espanha), e entre suas áreas de pesquisa estão a ética, a ecoética, a relação entre filosofia e felicidade, assim como questões de gênero. A obra, por sua vez, foi publicada na coleção Memoria de Mujer, da Editora da Universidade de Salamanca que, desde 2015, publica estudos sobre a mulher em todos os âmbitos científicos.

0 argumento fundamental da obra consiste em situar Rachel Carson como precursora do ecofeminismo. A partir dessa ideia chave, a autora desenvolve a temática contextualizando a cientista Rachel Carson e a sua obra, as fontes que inspiraram os seus estudos e, em especial, as relações sociais que Carson manteve ao longo de sua curta vida que, não obstante, foram decisivas em sua trajetória biográfica e profissional. Para isso, o livro revisa cronologicamente 0 conjunto da obra de Rachel Carson até chegar em Primavera silenciosa (Silent spring, título original), publicada em 1962, obra que a consagrou em razão da crítica social imbuída no livro. Entre as fontes, Castelo traz à luz correspondência pessoal da escritora com familiares, amigos e colegas de trabalho, documentos diversos elaborados por ela, além de obras biográficas sobre Carson.

Antes de avançar em considerações sobre o livro, cabe apresentar, brevemente, a cientista Rachel Carson. Rachel Louise Carson nasceu em 1907, e faleceu, devido a um câncer, com 56 anos, em 1964, nos Estados Unidos. Profundamente comprometida com a defesa do meio ambiente por meio da ciência, Rachel Carson é considerada uma das fundadoras do conservacionismo ecológico. Segundo Carmen Castelo, a obra de Carson inaugurou uma revolução ecológica: "Carson combinaba la madurez científica con la pasión literaria y esa mezcla de ciencia y compromiso dio como resultado una revolución" (p. 27). . $^{-1}$ 
Uma das características da obra de Rachel Carson é a boa acolhida que teve entre o público especializado e pelos leitores em geral. Segundo Castelo, isso se deve em parte ao rigor científico de seus estudos, em conjunto com uma prosa rica em imagens poéticas, fruto da sua visão acerca da humanidade integrada na natureza, sua valorização e amor. Portanto, no caso de Rachel Carson, o rigor na construção do conhecimento científico não seria incompatível com a paixão, o amor, e mesmo o deslumbramento pela natureza. Outro fator destacado no livro de Castelo com relação ao sucesso da obra de Carson entre o público em geral foi a sua divulgação em meios e formatos diversos, desde folhetos, passando por artigos em revistas femininas como a Vogue, até documentários exibidos na televisão.

Apesar do sucesso de grande parte de sua obra, e do reconhecimento que mais tarde Carson receberia em forma de prêmios, foi com Primavera silenciosa que Rachel Carson recebeu as maiores reações negativas, não pela metodologia científica empregada na pesquisa e na elaboração do trabalho, mas pelas críticas ao uso de pesticidas. Foi duramente atacada e desqualificada pessoal e profissionalmente.

Com relação às fontes que auxiliaram e influenciaram Carson na produção de sua obra, Castelo menciona um conjunto de obras publicadas ainda no século XIX, além de uma rede de mulheres cientistas, pesquisadoras sobre a natureza, a quem Castelo denomina proto-red ecofeminista. A obra de Rachel Carson foi publicada fundamentalmente nas décadas centrais do século XX. Por isso, seus textos encontraram eco entre um setor da sociedade americana que começava a olhar criticamente para os efeitos do progresso tecnológico e científico, que tiveram na bomba atômica 0 seu exemplo mais estarrecedor. Sobre isso, diz Castelo: "Pacifista e conocedora de los riesgos de las carreteras de gran velocidad, [Carson] nos explicaba la conveniencia de elegir el camino tortuoso, lento, pero respetuoso con la vida" (p. 22).

Com relação à estrutura, o livro se organiza em nove capítulos. Depois do prólogo, segue-se uma cronologia, "Rachel L. Carson su época", que parte de 1831, ano de nascimento de Olive Thorne Miller - antecessora de Carson na pesquisa e militância em defesa da natureza, autora de livros sobre aves e que teve grande influência na obra de Carson - até 1999, quando a Time Magazine incluiu Rachel Carson entre os vinte cientistas e filósofos mais importantes do século XX; sem deixar de lado datas emblemáticas da vida, da obra e do contexto histórico em que viveu Carson. 0 último capítulo do livro consiste em referências bibliográficas incontornáveis para quem desejar mergulhar na temática: uma lista das obras assinadas por Rachel Carson, outra sobre a autora, e finalmente, obras de consulta recomendada. Tal estrutura imprime ao livro um caráter extremamente didático e, ao mesmo tempo, de obra de referência (quase um manual) e síntese para uma primeira aproximação à figura de Rachel Carson e sua produção científica.

0 núcleo da obra está formado por quatro capítulos. 0 primeiro deles, "Una vida dominada por el asombro y la creatividad. La revolución inmanente", é o mais extenso, e nele Castelo nos apresenta a figura de Rachel Carson, sua biografia e obra. A abordagem escolhida pela autora do livro combina fatos biográficos - específicos de Rachel Carson e outros relativos às relações sociais que construiu e manteve ao longo de sua vida, com familiares, amigos, assim como com outros cientistas, com organizações sociais ambientalistas e de mulheres - com fatos históricos, porém não de forma estanque. 0 grande mérito do capítulo, além da qualidade das fontes utilizadas, é o de oferecer ao leitor um panorama da evolução de uma trajetória pessoal e de uma obra científica, que foram sendo construídas historicamente. A última parte desse capítulo aborda a elaboração de cinco livros e de uma série de folhetos produzidos durante o período em que Rachel Carson trabalhou no Serviço de Informação do Serviço de Pesca e Vida Silvestre do governo norte-americano.

Bajo el viento oceánico (1941, Under the Sea-Wind) é o primeiro livro de Rachel Carson que trata da vida marinha e das suas relações ecológicas. Sobre a elaboração dessa obra, escreve Castelo:

La escritura de este libro fue meticulosa. Cada noche, después de su trabajo para el gobierno, leía en alto lo escrito cuidando exhaustivamente la prosa, las aliteraciones y el sonido de las frases para crear la atmósfera requerida. Revisaba párrafo por párrafo, frase por frase. Incluso ciertos ritmos de la naturaleza quedaron reflejados en la cadencia de las oraciones (p. 41). 
The conservation in action é um conjunto de folhetos publicados entre 1947 e 1950, nos quais Carson, ocasionalmente com a colaboração de outros cientistas, explicava sobre algum lugar protegido de seu país. Nesse sentido, o tema que atravessava essas publicações tratava da conservação para a sobrevivência. Porém, não a necessidade de sobrevivência justificada pelo uso e exploração humana, mas

La 'preservación de la vida en estado natural' es, a su vez, la preservación de todo lo necesario para que la vida humana y no humana se desarrolle. En suma, la conservación es fundamental para sobrevivir una vez que sabemos que somos ecodependientes y necesitamos del resto de la vida natural (p. 47).

De acordo com o texto, teria sido a partir da experiência da produção desse material que Rachel Carson identificou, nas políticas públicas de conservação, a ausência de uma preocupação de fato com a "naturalidade dos ecossistemas". Ao final desse período de pouco mais de dois anos Rachel Carson deixaria o serviço público para dedicar-se exclusivamente à sua obra.

Se com as obras anteriores, de alguma forma, Rachel Carson havia conseguido conquistar certa notoriedade entre o público em geral, El mar que nos rodea (1951, The sea around us), seu segundo livro sobre o mar, coroou o sucesso de um estilo de redação, na época ainda pouco frequente. 0 reconhecimento público veio na forma do prêmio nacional do livro na categoria de obra não ficcional e com a medalha John Burroughs. Além disso, encabeçou as listas de livros mais vendidos, segundo o The New York Times (p. 51). Sobre esse livro (e as publicações anteriores), cabe destacar:

Si de algo nos puede servir volver la mirada hacia estos libros, será el análisis de como influyeron en las relaciones humanas con el entorno y de cómo potenciaron el deseo y la actitud de conservación. [...] Quizá Rachel aun pueda servirnos para encontrar nuestro propio lenguaje, ese que nos conduzca por los caminos más transitables ante los problemas a los que nos enfrentamos (p. 54).

0 terceiro livro sobre o mar é En el borde del mar (The edge of the sea, 1955), que recebeu uma ótima crítica e, novamente, ficou entre os títulos mais vendidos, segundo o Times (p. 55). Sobre esse título ressalte-se, além da habilidade da escritora para despertar nos leitores sentimentos positivos sobre o seu objeto de pesquisa, as ilustrações de Robert W. Hines: “Carson incorporó el arte del dibujo em casi todas las publicaciones [porque] presentan plásticamente lo que el texto explica. La coalición de arte y ciencia es sencillamente omnipresente en la obra de Carson" (p. 55).

Algo sobre el cielo (1956, Something about the sky) é o texto para um documentário sobre nuvens transmitido na televisão em março de 1956. Sobre o contexto de desenvolvimento desse trabalho, Castelo destaca a importância do contato entre Carson e o fotógrafo Vicente Lois Schafer, que lhe havia ensinado a usar um adaptador para acoplar uma câmera fotográfica a um microscópio (p. 58).

Finalmente, chega-se a Primavera silenciosa (1962, Silent spring). Sendo o título mais conhecido de Rachel Carson, compreende-se que Castelo the dedicasse, em seu livro, um espaço mais amplo e maiores considerações. Porém, não foi somente por isso. Primavera silenciosa, ao mesmo tempo em que teve um impacto profundo sobre a sociedade norte-americana da época (Castelo cita o fato de o presidente Kennedy, em uma coletiva de imprensa, ter mencionado o texto, até então publicado somente em fascículos no The New Yorker, portanto antes de seu formato como livro), rendeu a Carson os piores ataques e críticas.

0 tema do livro é a capacidade humana de destruir a natureza (especialmente as aves) por meio do emprego de substâncias químicas como o diclorodifeniltricloroetano, mais conhecido como DDT.

A ojos de Rachel Carson, como científica y observadora incansable, probablemente sea la capacidad contaminante del hombre con sustancias peligrosas, junto con la radiación, el mayor atentado contra los ecosistemas y la vida (p. 60). 
0 texto apresenta o processo de pesquisa de Carson, assim como o contexto de surgimento e uso disseminado de DDT nos cultivos agrícolas nos Estados Unidos. Além de ser considerada, provavelmente, a obra inaugural de divulgação científica sobre o impacto ambiental, Castelo nos apresenta o que poderíamos qualificar como a controvérsia científica gerada pela obra entre grande parte da comunidade científica, que, na época, estava a favor do uso dessa substância para o controle de pragas nos cultivos. À época, outro importante ator social somava-se ao debate: as empresas químicas, que não poderiam permitir que o discurso de Carson se difundisse tão amplamente. A solução escolhida por esses setores foi a desqualificação da escritora. Acusavam-na de ter escrito uma obra "apaixonada" e "pouco equilibrada" (p. 69), ou seja, pouco científica. Entre os demais setores ecoavam críticas a sua pessoa e, inclusive, ao seu gênero:

Es increíble que el machismo de estas afirmaciones sea compatible con otro sesgo común en su momento, esto es, el especismo fuerte, de modo que tanto ser mujer como preocuparse por nuestros hermanos animales contara en negativo. Esto se une por esa lógica de dominio patriarcal que excluye a mujeres y animales no humanos del club moral (p. 69).

Finalizando essa seção do seu livro, Castelo afirma que Primavera silenciosa, ao oferecer importantes impulsos para a luta ambiental, abriu o debate público entre especialistas e não especialistas sobre um aspecto chave da ecologia: a ideia de que as ações sobre a natureza não têm consequências apenas sobre esta, mas sim sobre o meio natural e social como um todo.

Finalmente, no capítulo 7, para o desenvolvimento do conceito de ecofeminismo, Castelo amarra todas as ideias trabalhadas nos capítulos anteriores. Para Castelo, Carson pode ser considerada a mãe do ecofeminismo porque "argumentó a favor de una visión dignificada tanto de las mujeres como de la naturaleza" (p. 95), defendeu uma maneira diferente de abordar o tema ambiental, que fosse a partir do cuidado, incluindo emoções, como o amor "hacia lo que se quiere proteger" (p. 95). E residia aí a novidade do discurso de Carson, uma vez que esta perspectiva, do amor, do cuidado, e até do deslumbramento (diferente da observação e experimentação), não estava presente nem mesmo na ecologia naquele momento. Mais adiante no texto Castelo assevera sobre o ecofeminismo:

El ecofeminismo continúa la tendencia dirigida a completar la moralidad vigente con valores como la responsabilidad, el énfasis en lo particular, el cuidado y la empatía. Solo que esta vez el cuidado lo es también de la naturaleza, las relaciones de responsabilidad no se limitan a la comunidad humana y el énfasis en las diferencias frente a la uniformidad de las categorías abstractas y homogeneizadoras de la ética Moderna debilita las fronteras entre la humanidad y el resto de la naturaleza, así como dibuja en su lugar espacios de convivencia y comunidad diferenciada (p. 96-97).

Nesse sentido, a defesa que Castelo faz de Carson como fundadora do ecofeminismo tem especial interesse, porque nos permite compreender a pessoa e a obra de Carson em uníssono, o cuidado e a dedicação à família, o deslumbramento diante da natureza, e uma advertência não apocalíptica dos estragos que vinham sendo produzidos no meio ambiente, já na época visíveis e quantificáveis pela ciência. Mas, também, por meio da leitura dos fragmentos dos textos selecionados, se depreende igualmente uma visão de amor a uma certa maneira de produzir conhecimento científico.

Finalmente, a leitura da obra de Rachel Carson por intermédio do livro de Castelo no atual contexto de pandemia de covid-19 leva-nos a refletir sobre a relação que mantemos, hoje, em pleno século XXI, com o nosso entorno e as populações humanas e não humanas que nele habitam. E, ao mesmo tempo, podemos questionar-nos sobre o tipo de ciência que produzimos ou que queremos produzir. Se, para Carson, só se protege aquilo que se ama, também só se ama aquilo que se conhece.

1 Todas as citações que constam neste texto foram retiradas da obra resenhada, por isso, na chamada às referências será incluído apenas o número da página correspondente. 